\title{
I had found my passion, all of it!'
}

Stacy Topping, 33, from Lisburn in Northern Ireland, is a senior dental nurse at the South Eastern Health and Social Care Trust; dental continuing education coordinator - Northern Ireland Medical and Dental Agency (NIMDTA); and an examiner for NEBDN. She has post-graduation certificates in dental implant nursing, dental radiography, dental sedation nursing and oral health education, three ILM qualifications including Level 5 Leadership and Management, and a Level 3 Award in Education and Training. Stacy is married and has 'a beautiful lockdown baby called Henry'.

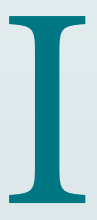

' $m$ such a home bird and have never lived anywhere except Lisburn. I wish I could say my usual wake up time is around $8 \mathrm{am}$, but it's more - what do they say, the early bird catches the worm?

Breakfast - what's that? There is just not enough time in the morning. I don't usually eat something until break time (if I'm lucky).

My go-to recently has been a banana and coffee.

I work full time, Monday to Friday, just not in the same job.

On a Monday and Tuesday when I'm working as a dental continuing education coordinator, and if I'm heading to the office, it takes me about 20 minutes to get to work in the car. I am so fortunate with my position in NIMDTA that I get to travel to different locations around Northern Ireland when facilitating courses.

Being a dental continuing education coordinator involves delivering training

\section{'I have been entirely lucky in my dental} nurse career that job positions arose

at the right time; fast forward to the present day and here I am sitting with two different but amazing jobs.'

to dental professionals, supporting and maintaining clinical skills facilities including phantom heads, promoting the courses NIMDTA are providing, representing NIMDTA at meetings and conferences, designing and developing the dental education programme with a team, and facilitating courses ensuring they meet the aims and objectives.
On a South Eastern Trust day when I'm working as a senior dental nurse I can be working in various locations across the North Down Ards sector, and my travel time can be anything from 45 to 90 minutes. On these days I could be doing anything from working clinically with multidisciplinary teams, creating staff rotas, granting annual leave, ordering stock, chairing meetings, ensuring 
service and maintenance of equipment is up to date, carrying out risk assessments or participating in staff recruitment and appraisals. Some days I can be working within the Ulster hospital assisting with paediatric extractions under general anaesthetic, or within nursing homes carrying out screenings, in patients' own homes, or assisting with aerosol-generating procedures (AGPs) in one of our two clinics.

My sister is a dental nurse as well as three of my cousins - can you imagine the talk around the dinner table? I always thought dental nursing would be a good career choice, but when I was at school I wanted to be a PE teacher, and that was reflected in my A-level choices.

Dental nursing wasn't my first choice, and speaking to other dental nurses this always seems to be the case. I don't think enough emphasis is put on what a great career choice it can be when studying at school.

I first started working in general practice. I remember my first day being so scared to even hold the suction tip. I learnt so much and had an excellent mentor: my cousin!

I started general practice in May and by the September I had enrolled in my local college in the evenings to complete the NEBDN national certificate for dental nurses. It was an intense first year, but totally worth it. I had passed my exam by the following year, first time around - does anyone else remember the old style oral?

Five years after passing my exam I started to get a bit bored and thought if I don't do something else I may leave dental nursing and pursue another career. That's when I started looking at post qualifications. My practice carried out both intravenous sedation and inhalation sedation so that was my choice for my first post qualification. The education bug had well and truly been bitten. I started a new dream job in the evenings teaching dental nurses dental sedation; I enjoyed passing on my skills and knowledge and felt I was making a difference. After my sedation exam I quickly enrolled in my next qualification, dental implant nursing, alongside completing a competency in dental impression taking.

I had gained so many skills from general practice; I had progressed through the practice working with the principal dentist with private patients; I assisted with everything from prosthetics, cosmetic dentistry, oral surgery and even facial aesthetics; I loved every minute there, but after eight years it was time to move on.

Around this time the NEBDN were recruiting examiners and I was accepted! I travelled to Birmingham to train on how

to examine dental nurses in the OSCE [Objective Structured Clinical Examination] setting. I have made so many friends and memories from examining in Belfast and London. COVID then hit and the OSCEs moved to Zoom. Fingers crossed next year we can all meet in person again!

This is when I started my new role within the School of Dentistry (SOD), Belfast. This was an entirely new role; I had never worked in a hospital setting, and was eager to learn! I started working four-handed with undergraduate dental students. I enjoyed giving them advice and hope I played a part in helping developing their skills. From here I rotated through each and every department: conservation, periodontal, prosthetics, walk in emergencies, orthodontics, total patient care, oral surgery and general anaesthetics within the day procedure unit (DPU). I had gained so many skills from each and every dental nurse (and clinician) I worked with. I had found my passion, all of it! So when an opportunity came to work permanently in a department I grabbed it: the children's

\section{'I have a passion for dental nurse}

\section{education; I want to encourage}

\section{all dental nurses to further their}

\section{education and career in dentistry."}

hospital - where else would I get to use every skill I gained in each department?

Alongside working in the SOD, I started working in my local college teaching trainee dental nurses - how did I get so lucky?

Over two years ago, a senior dental nurse position was advertised in the community dental service. I applied and was successful at interview - I started a new career path in dentistry and management. The Community Dental Service was completely new to me; I was able to learn new skills and pass on some of the skills I have picked up on the way to the nurses I am working with. No two days are the same!

I have been entirely lucky in my dental nurse career that job positions arose at the right time; fast forward to the present day and here I am sitting with two different but amazing jobs. My dream job in dental education at NIMDTA has become my reality. I started my new role as a dental continuing education coordinator in June of this year dental phobic patient to sit in the dental chair.

I usually get home around $5.30 \mathrm{pm}$.

Outside work I enjoy nothing more than going out for a long walk and catching up with friends for a coffee. Since having my son Henry his interests have now become my interests. We spend our Sunday mornings in the swimming pool and are soon to enjoy Saturday afternoons playing football.

With working full-time, it is important to spend quality time together as a family. I always try to have something planned or booked for the weekend. It could be anything from a walk up the Mourne Mountains, soft play areas, or visiting my grandparents.

With so many TV series and movies at our fingertips these days, I normally don't get into bed until $11.30 \mathrm{pm}$ - I really need to catch up on some beauty sleep!

\section{Interview by Kate Quinlan}

https://doi.org/10.1038/s41407-021-0768-8 